\title{
Urban climate change: A comprehensive ecological analysis of the thermo-effects of major Chinese cities
}

\author{
Jinlou Huang*, Rusong Wang, Yao Shi \\ State Key Laboratory of Urban and Regional Ecology, Research Center for Eco-Environmental Science, Chinese Academy of Sciences, 100085 Shuangqing Road 18\#, \\ Haidian District, Beijing, China
}

\section{A R T I C L E I N F O}

\section{Article history:}

Received 18 May 2008

Received in revised form 1 November 2009

Accepted 1 November 2009

Available online 28 November 2009

\section{Keywords:}

Urban climate change

Urban thermo-effects

Air temperature

Multiplied regression analysis

Grey System Theory

System core and coritivity

\begin{abstract}
A B S T R A C T
Using 89 major Chinese cities which comprise the case study area, this article computed the urban thermo-effect of summer in the 1990s and 2000s compared to that in the 1950s, using the database of highest monthly temperatures recorded by national weather stations from 1951 to 2007 . We conducted a temporal-spatial analysis of the calculated urban thermo-effect, after which we carried out grey correlation degree analysis, system core and coritivity computation of the 22 selected indicators that could affect the urban thermo-effect. These were performed in order to determine the main factors for comprehensive analysis of urban thermo-effect. Finally, we conducted multiple regression analysis between the computed urban thermo-effect and the main factors to create the comprehensive ecological model of the urban thermo-effect. The results indicate that the urban thermo-effect in the 2000s compared to that in the 1950 s is stronger than that in the 1990s. Meanwhile, the respective maximum urban thermo-effects in the 2000s and in the 1990s compared to that in the 1950 s are $1.97 \mathrm{~K}$ and $1.50 \mathrm{~K}$, respectively. The strong positive urban thermo-effect occurred mainly in the northeastern Chinese cities during the 1990s, while it occurred in the northwestern cities and southeastern coastal cities during the 2000s. The six main factors of the urban thermo-effect are the total size, the Gross Domestic Product (GDP), the green area, and the population of the built-up area, as well as the gross of freight and annual electricity consumption. The multiple comprehensive ecological model of the urban thermo-effect is reliable because the residual error of the created model is smaller than $0.5 \mathrm{~K}$. The study discovers that the mitigation of urban temperature increase is possible with the adjustment of these controllable factors. Moreover, the findings in this article could provide references to decisions made while carrying out urban planning and while implementing policies in the national and local scale. Our findings can also provide references to the urban planning and construction of other developing countries with high levels of urbanization and economic development.
\end{abstract}

(c) 2009 Elsevier B.V. All rights reserved.

\section{Introduction}

Regional and local climate change is more rapid than global climate change and directly affects the activities of local people. To be specific, urban climate change is a kind of local climate change caused by rapid urbanization, which occurs mainly in developing countries experiencing rapid economic development. The most impressive phenomenon is the urban thermo-effect, which refers to thermal environment changes within the area due to the alteration of energy balance (Oke, 1982, 1988). The urban thermoeffect may cause the Urban Heat Island phenomenon during which the temperature of an urban area becomes higher than that of the surrounding rural area, resulting in a high rate of heat-related

\footnotetext{
* Corresponding author. Tel.: +8613 910656532; fax: +861062943807. E-mail address: lyphjl@hotmail.com (J. Huang).
}

diseases and mortality (Kalkstein, 1993; Semenza et al., 1996; Kalkstein and Greene, 1997; Smoyer, 1998), high consumption of energy for air conditioning (Le Comte and Warren, 1981; Santamouris et al., 2001), and air pollution (Aikawa et al., 2006; Sarrat et al., 2006; Noyes et al., 2009).

To mitigate the negative impact of the urban thermo-effect and improve the well-being of the local people, we need to determine the main reasons for this phenomenon. On the one hand, the regional climate change due to global warming can certainly influence the urban thermo-effect but only account for a small portion. For example, Ren et al. (2005) concluded that in China, the average air temperature during summer increased by $0.15 \mathrm{~K}$ degree every 10 years for the past 50 years. On the other hand, the urban thermo-effect had little impact on regional temperature change (Li et al., 2004). Thus, we can state that the urban thermoeffect is mainly caused by local factors. Indeed, former studies have focused on local factors such as the meteorology and climate (Djen, 
1992), urban population (Oke, 1973; Xiao et al., 2008), urban land use or cover change (Weng and Yang, 2004; Kardinal Jusuf et al., 2007; Li et al., 2009), and anthropogenic heat emission (Taha, 1997; Fan and Sailor, 2005), to name a few, while ignoring the integrated impact of multi-factors, thus overlooked the interactions among them, then could not caught the emergent phenomenon of the complex system ( $\mathrm{Li}, 2000$ ). Unfortunately, previous studies were lacking in terms of dynamic simulation of temperature, and their objects were often unclear.

An urban area is a kind of complex socio-economic and natural ecological system (Ma and Wang, 1984), so the factors that affect the urban thermo-effect should also include social, economic, and natural factors. As such, we carried out a comprehensive ecological analysis of the urban thermo-effect using the angle of system theory. According to the principles of complexity science, although we could not list all the factors affecting the urban thermo-effect, we can learn about the general rules and characteristics of its complex system by utilizing some factors and their dynamic interaction (Green and Sadedin, 2005). We can then determine the main factors that contribute to the stability of the whole system which, in turn, by building a qualitative conceptual model (Dresner, 2008), will allow the decision maker to consider these in making the decision.

The Grey system is a kind of "partial information known, partial information unknown" system. Created by Julong Deng in 1982 (Deng, 1982), the Grey System Theory refers to the studies on the model creation, forecast, decision making, and optimization of the Grey system through limited known information (Liu, 2003). Since then, research on theory development and applications has progressed, and this theory has been widely utilized in industrial, agricultural, and environmental applications (Qiao et al., 2006), economic, social, management, military, earthquake forecasting, and transportation applications, as well as oil exploration, among others. However, until today, nearly all researchers of the Grey System Theory are from Chinese speaking areas, and the theory is still relatively unknown and not as widely accepted in the western world (Lu and Wevers, 2007). In China however, the application of the Grey System Theory has achieved great success. For example the topography grey forecasting of the Yellow River Delta won a grant of 3 billion RMB (Li et al., 2002), while the forecasting of the plant diseases and insect pests in Hebei province won 1.5 billion RMB.

Meanwhile, the System Core Theory was initiated by Wang et al. (1993a) and Xu (1999) based on the system theory and the principles of cybernetics. By considering the existing system in the world, they found that there were either one or more factors which account for important positions within every system, whether natural or social. If these factors were removed, the structure and stability of the system would suffer a severe impact, such as the androecium and gynoecium of the wheat follow, the brains of a human being, and the queen bee in a colony. To elaborate on their discussion, they introduced the concept of the system core, which states that the androecium and gynoecium are the cores of a wheat follow, the brain is the core of a human being, and the queen bee is the core of a colony. Similarly, cores also exist within the urban system, and they decide the changes in the rules of the urban thermo-effect.

This article used 89 major Chinese cities which comprise the case study area. First, we computed the changes in average air temperatures in the hottest month in the decades between the 2000 s and the 1950s and between the 1990s and the 1950s, based from the monthly air temperature database of urban weather stations. In this article, these represent the urban thermo-effects during the 2000s and the 1990s. We then analyzed the distribution of the urban thermo-effect around the whole country at that time. Second, using the Social-Economic-Natural Complex Ecosystem theory, we listed as many factors as possible, including social, economic, and natural ones, which could affect the urban thermoeffect. We then calculated the grey correlation degrees between each pair of factors generated from all the listed factors by integrating the Grey System Theory. Based on the results of the grey correlation degrees, we applied the system core and coritivity theory to determine the main factors of the urban thermo-effect. Finally, the multi-regression analysis between the main factors and the value of the urban thermo-effect was carried out to complete the creation of a comprehensive ecological model of the urban thermo-effect. This article aims to answer the following questions:

- How did the urban thermo-effect change during the rapid economic development of China in the past 50 years?

- What were the main factors that affected urban thermo-effect?

- How can the controllable factors be adjusted to mitigate the increasing urban temperature?

\section{Methods}

\subsection{Study area and data source}

\subsubsection{Study area}

China lies in the east of the Asian Continent and in the west of the Pacific, and has a total area of 9.6 million $\mathrm{km}^{2}$. Most of the Chinese mainland belongs to the North Temperate Zone characterized by a continental monsoon climate which is clearly suitable for living. Moreover, it is distributed along six temperate zones from south to north including the Equatorial, Tropical, Subtropical, Warm Temperate, Temperate, and Boreal Zones. The amount of precipitation is diverse around the whole country, as it decreases from the southeast to the northwest. For example, it could reach 1500 millimeters in the southeastern coastal area, but only 200 millimeters in the northwest inland.

Since China established reforms and opened its doors in 1978, it has seen a rapid increase in the rate of urbanization it has experienced. According to the report from the National Bureau of Statistics, 661 cities in China comprise a population reaching a total of 577 million, which accounts for $43.9 \%$ of the entire population of the country. Admittedly, vigorous economic development can pave the way toward improved living conditions. However, urban temperatures in most of these cities are also increasing due to land use or cover change for the built-up area, as well as due to the huge amount of anthropogenic heat emission generated by energy consumption during industrial activities.

In this article, we selected 89 major Chinese cities, including the capital cities of the provinces and those that have urban weather stations. The total Gross Domestic Product (GDP) of the 89 cities selected amounted to 60,000 billion RMB, which accounted for two thirds of the GDP of the whole country, while the total population was about 650 million, which accounted for over half of the whole population in 2004. Thus, these cities are considered representative of China and are also the focus cities of the government. We used these to comprise the case study area and carried out a comprehensive ecological analysis of the urban thermo-effects occurring in these cities, which could provide suggestions for the national and local government. These can also provide references to the urban planning and construction of other developing countries with rapid rates of economic development. The study area and the distribution of the selected cities are shown in Fig. 1.

\subsubsection{Data sources}

2.1.2.1. Climate data. China is located at the Northern Hemisphere, with its highest temperature occurring in the summer. Thus, the 


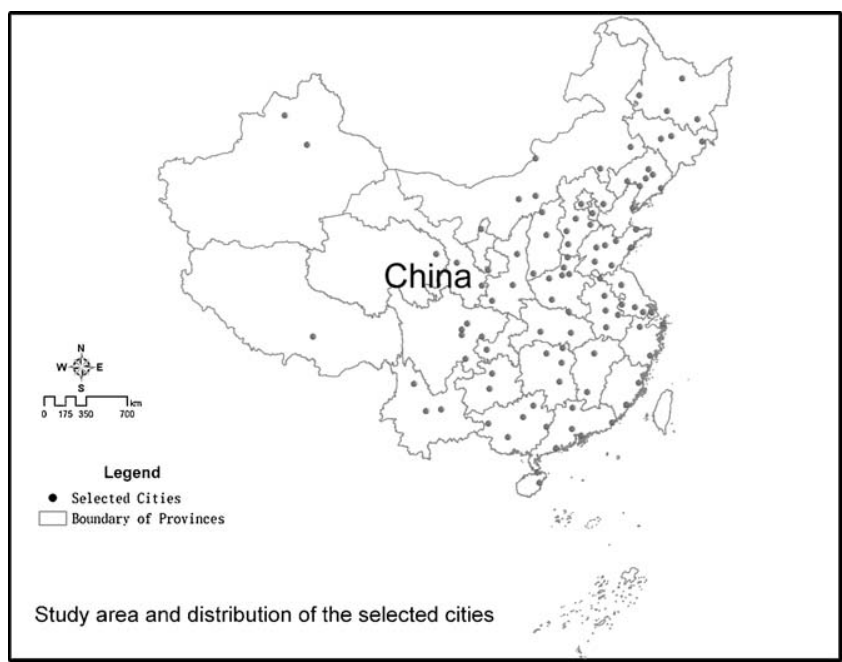

Fig. 1. The study area and the distribution of the 89 selected cities.

emphasis of this article is the urban thermo-effect during summer. According to the analysis, the average monthly temperature fluctuates annually and is not representative, while changes of average monthly temperature through the decades can be an indicator of the urban thermo-effect changes.

We utilized the highest average monthly temperatures recorded from 1951 to 2007 by national urban weather stations located in the cities mentioned.

2.1.2.2. Indicator selection and data collection. In the study of urban thermo-effect, we considered 22 indicators which could affect it and these include: GDP, population, size of the built-up area, gross of passenger transport, gross of freight, water supply, and electricity consumption of cities, among others. They could be divided approximately into five types of factors: energy utilization and emission, coverage, transportation, economic development, and population. Detailed indicators are listed in Table 1. Data related to indicators of the 89 cities sampled came from the 2005 annual statistics of these Chinese cities.

\subsection{Urban thermo-effect of surface air temperature}

The average highest monthly temperature during the 1950s, 1990s, and 2000s were calculated using the highest monthly temperature data of summer recorded by urban weather stations in the past 50 years. We deducted the average highest monthly temperature in the 2000s and 1990s from that in the 1950s, which separately represented the urban thermo-effect of summer in 2000 s and 1990s compared to that in the 1950s. The formulae were as follows:

$\Delta T_{90}=T_{90}-T_{50}$

$\Delta T_{2000}=T_{2000}-T_{50}$

where $\Delta T_{2000}$ and $\Delta T_{90}$ denote the urban thermo-effect of the respective summer seasons of the 2000s and the 1990s.

$T_{2000}=\frac{\sum_{j=1}^{n} T_{j}}{n}, \quad T_{90}=\frac{\sum_{i=1}^{m} T_{i}}{m}, \quad T_{50}=\frac{\sum_{k=1}^{p} T_{k}}{p}$

where $T_{2000}$ denotes the average highest monthly temperature in cities from 2000 to 2007 with $j=\{1,2,3,4,5,6,7,8\} ; T_{90}$ denotes the average highest monthly temperature in cities from 1990 to 1999 with $i=\{1,2,3,4,5,6,7,8,9,10\}$; and $T_{50}$ denotes the average highest monthly temperature in cities from 1951 to 1959 with $k=\{1,2,3,4,5,6,7,8,9\}$.

\subsection{Main factors in screening for the urban thermo-effect}

\subsubsection{Grey correlation analysis for every pair of factors compared}

Grey correlation degree is an indicator used to measure the relative variations between two systems or two factors, which describes the relative changing status of two factors such as their value, direction and speed, during the developing process of a system. If the relative changing status of two factors is basically consistent, then they have a high degree of grey correlation and vice versa. In relation with this, the grey correlation analysis is a method based on the grey correlation degree. It is used to analyze and determine the relationships between different factors within a

Table 1

Indicators affecting the urban thermo-effect and their types.

\begin{tabular}{|c|c|c|c|}
\hline Code & Name of indictors & Unit & Influencing types \\
\hline A & GDP of the built-up area & RMB Yuan & Economy development \\
\hline B & Population of the built-up area & ten thousand people & Population \\
\hline $\mathrm{C}$ & Size of the built-up area & $\mathrm{km}^{2}$ & Coverage \\
\hline $\mathrm{D}$ & Gross of passenger transport & ten thousand ton & Transportation \\
\hline $\mathrm{E}$ & Gross of freight & ten thousand people & Transportation \\
\hline $\mathrm{F}$ & Annual water consumption & ten thousand $\mathrm{m}^{3}$ & Energy utilization and emission \\
\hline G & Annual electricity consumption & Kwh & Energy utilization and emission \\
\hline $\mathrm{H}$ & Electricity consumption per person & Kwh & Energy utilization and emission \\
\hline I & Coal gas supply & ten thousand $\mathrm{m}^{3}$ & Energy utilization and emission \\
\hline $\mathrm{J}$ & LPG gas supply & ton & Energy utilization and emission \\
\hline $\mathrm{K}$ & Road area at the end of the year & ten thousand $\mathrm{m}^{3}$ & Coverage, transportation \\
\hline $\mathrm{L}$ & Road area built per person & $\mathrm{m}^{2}$ & Coverage, transportation \\
\hline M & Number of buses for commercial use at the end of the year & vehicle & Transportation \\
\hline $\mathrm{N}$ & Number of public buses & vehicle & Transportation \\
\hline $\mathrm{O}$ & Number of taxis at the end of the year & vehicle & Transportation \\
\hline $\mathrm{P}$ & Waste water from industry & ten thousand tons & Energy utilization and emission \\
\hline Q & $\mathrm{SO}_{2}$ emission from industry & ton & Energy utilization and emission \\
\hline $\mathrm{R}$ & Soot emission from industry & ton & Energy utilization and emission \\
\hline $\mathrm{S}$ & Gardening green area & ha & Coverage \\
\hline $\mathrm{T}$ & Green area per person & $\mathrm{m}^{2}$ per person & Coverage \\
\hline $\mathrm{U}$ & Green area of built-up area & ha & Coverage \\
\hline V & Coverage percent of green area & $\%$ & Coverage \\
\hline
\end{tabular}


system and to calculate their contribution to the running rules within it.

In this article, we carried out grey correlation analysis of the selected 22 indicators using the following processes: data standardization, calculation of grey correlation coefficient between different indicators, and calculation of their grey correlation degree.

2.3.1.1. Data standardization. If the factor or variable that we wanted to explore had a different definition, order or unit, the adjustment and transformation was taken to eliminate the difference between the two series. In this study, the equalization method was used to obtain the comparable series. This meant that the value of the reference series and compared series was normalized by dividing the respective data of the original series by its mean value.

Supposing the original data series:

$$
x^{(0)}(i)=\left\{x^{(0)}(1), x^{(0)}(2), \ldots, x^{(0)}(n)\right\}
$$

$$
\begin{aligned}
x^{(1)}(i) & =\left\{\frac{x^{(0)}(1)}{\bar{x}^{(0)}}, \frac{x^{(0)}(2)}{\bar{x}^{(0)}}, \ldots, \frac{x^{(0)}(n)}{\bar{x}^{(0)}}\right\} \\
& =\left\{x^{(1)}(1), x^{(1)}(2), \ldots, x^{(1)}(n)\right\}
\end{aligned}
$$

where $x^{(0)}(i)$ denotes the original data series; $i$ denotes the number of factor; $n$ denotes the number of data series of each factor; $x^{(1)}(i)$ denotes the value of equalization treatment to $x^{(0)}(i)$; and $\bar{x}^{(0)}$ denotes the mean value of the original data series.

2.3.1.2. Grey correlation coefficient. The grey correlation degree between two series at a certain point is called the grey correlation coefficient. Consequently, the grey correlation coefficient $\zeta_{o j}(i)$ of compared series $x_{j}(i)$ to reference series $x_{0}(i)$ can be expressed as:

$\zeta_{o j}(i)=\frac{\min _{j} \min _{i}\left|x_{0}(i)-x_{j}(i)\right|+\rho \max _{j} \max _{i}\left|x_{0}(i)-x_{j}(i)\right|}{\left|x_{0}(i)-x_{j}(i)\right|+\rho \max _{j} \max _{i}\left|x_{0}(i)-x_{j}(i)\right|}$

where $x_{0}$ and $x_{j}$ are the reference series and compared series after normalization; $\left|x_{0}(i)-x_{j}(i)\right|$ represents the absolute difference between two series; $\min _{j} \min _{i}\left|x_{0}(i)-x_{j}(i)\right|$ and $\max _{j} \max _{i} \mid x_{0}(i)-$ $x_{j}(i) \mid$ denote the distance for each data in all compared sequences, and $\rho$ is the distinguishing coefficient used to adjust the difference of the correlation coefficient, usually $\rho \in(0,1)$ (Deng, 1988, 1989). According to the sensitivity analysis by Chang and Lin (Chang and Lin, 1999), the suggested value of the distinguishing coefficient, $\rho$ is 0.5 , due to the moderate distinguishing effects and good stability of outcomes. Therefore, we adopted $\rho=0.5$.

2.3.1.3. Grey correlation degree. The grey correlation degree represents the relative variations between one major factor and all other factors in a given system. The correlation degree between two sequences can be expressed by dividing the correlation coefficient by its average value, in order to show the relationship for the entire system (Deng, 1982), using $\gamma_{o j}$ to measure it. Thus:

$\gamma_{o j}=\frac{1}{N} \sum_{i=1}^{N} \zeta_{o j}(i)$

where $\gamma_{o j}$ denotes the grey correlation degree of each pair of factors, and $\mathrm{N}$ denotes the length of the series of factors.

In our study, all the computations were carried out by means of the statistical analysis software DPS for Windows 2003 (http:// www.chinadps.net/index.htm).

\subsubsection{Calculation of system core and coritivity}

The basic thought of "system core and coritivity" is that different factors have different roles and functions, some play key roles, while others are inconspicuous in the whole system. We named the group of key factors as the system core, and the tool for measuring this is called coritivity (Wang et al., 1993b).

Supposing that $x_{1}, x_{2}, \ldots, x_{n}$ are certain factors in the system $X$, we use $x_{i} x_{j}$ to represent the relationship between $x_{i}$ and $x_{j}$. Through this, we could construct the network graph $G$ of that system, then the vertex set of $G$ would be $V(G)=\left\{x_{1}, x_{2}, \ldots, x_{n}\right\}$, and the edges set of $G$ would be $E(G)=\left\{x_{i} x_{j}\right.$; there is a relation between $x_{i}$ and $\left.x_{j}\right\}$. Based on the above, we can consider $h(G)$ as the coritivity of the system graph G. Meanwhile, if

$h(G)=\max \{\omega(G-S)-|S| ; \quad S \subset C(G)\}|V(G)|=n \geq 4$

where $C(G)$ denotes the set which is constituted by all cutset of graph $G$, and $\omega(G-S)$ denotes the branch number which subtract cutset $S$ of graph $G$; if $S^{*}$ satisfies the following formula, then $S^{*}$ would be considered the core of this system.

$h(G)=\omega\left(G-S^{*}\right)-\left|S^{*}\right|$

Thus, the complicated issues of the system were transferred onto the network graph issues by solving the qualitative question with the quantitative method. Based on the significant analysis of the urban thermo-effect in this article, we decided that if the grey correlation degree is over 0.9 , then there exists an edge joining them in the system network graph. Finally, we produced the topological graph for the comprehensive ecological analysis system of the urban thermo-effect which used each factor as the vertexes, and used the joining of the grey correlation degree as the edges.

2.3.3. Principles for the main factors screening in the comprehensive ecological analysis of the urban thermo-effect

From the definition of "system core and coritivity," the bigger the system core and the more branches of topological graph existing upon core removal, the less stable the given system will be. In this study, we combined the actual meaning of the system of comprehensive ecological analysis for urban thermo-effect according to the core and coritivity analysis described above and applied the following principles during the screening for the main factors:

(1) There were correlations among factors within the same system, according to which, as well as to the running rules of factors, the topological graph we determined was comprised of indicators that should represent the entire relationships of all factors as comprehensively as possible.

(2) If a system core was bigger, there will be more braches in existence after the core was removed; on the other hand, the less stable the system was, the system core $C$ selected must satisfy the situation as follows:

$\omega(G-C)=\max \left[\omega\left(G-S_{i}^{*}\right), \quad i=1,2, \ldots, n\right]$

(3) After the core $\mathrm{C}$ of the system was selected, we simplified it by removing the redundancy of the system core according to the actual meaning of each indicator and then determined the final indicators of comprehensive ecological analysis for the urban thermo-effect.

\subsection{Creation of the comprehensive ecological model of the urban thermo-effect}

\subsubsection{Statistical characteristics analysis for each main indicator}

The statistical analyses of each indicator selected by system core and coritivity calculation were carried out through SPSS 


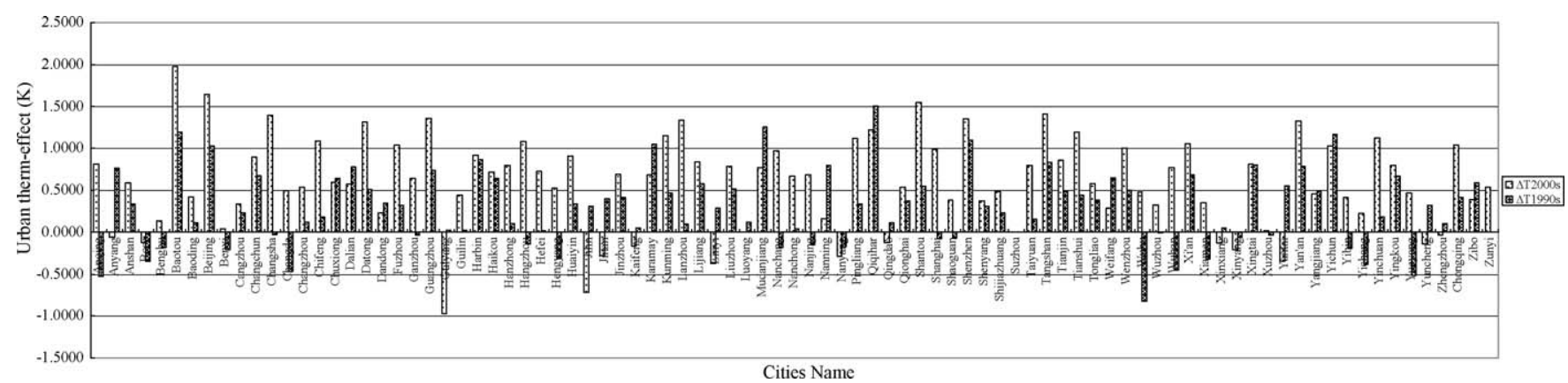

Fig. 2. The urban thermo-effect in the 2000s and 1990s compared to the 1950 s in the 89 selected major Chinese cities.

software for Windows. We tested the data's statistical distribution characteristics in preparation for establishing a comprehensive ecological model of the urban thermo-effect. This was carried out through the multiple regression analysis method.

\subsubsection{Model creation}

We supposed the basic theoretical form of the comprehensive ecological model for the urban thermo-effect to be as follows:

$\Delta T=f\left(x_{1}, x_{2}, x_{3}, \ldots, x_{k}\right)$

where $\Delta T$ refers to the urban thermo-effect of each selected cities, and $x_{1}, x_{2}, x_{3}, \ldots, x_{k}$ denote the main factors of the urban thermoeffect.

We then carried out the multiple regression analysis of data gathered on the urban thermo-effect, as well as the main factors of the 89 selected cities, using the software SPSS and EViews for Windows 2003. This resulted in the creation of the practical model of comprehensive ecological analysis.

\section{Result and discussion}

\subsection{Urban thermo-effect of surface air temperature in Chinese cities}

Fig. 2 shows the urban thermo-effect of all the selected 89 major Chinese cities in the 1990s and 2000s compared to the data in the 1950s, while Fig. 3 lists their maximum, minimum, and mean values. Generally, the urban thermo-effect in the 2000s was stronger than that in the 1990s. The top five cities with high urban thermo-effects in the 1990s were Qiqihar, Mudanjiang, Baotou, Yichun, which lies in north China, and Shenzhen, which lies in south China (Table 2). Data from these cities signify that urban thermo-effects may be influenced by the dry regional climate during the relatively slow urbanization in the 1990s. We can also see from the table that the biggest urban thermo-effect is $1.50 \mathrm{~K}$ degree. The top five cities with high urban thermo-effects in the

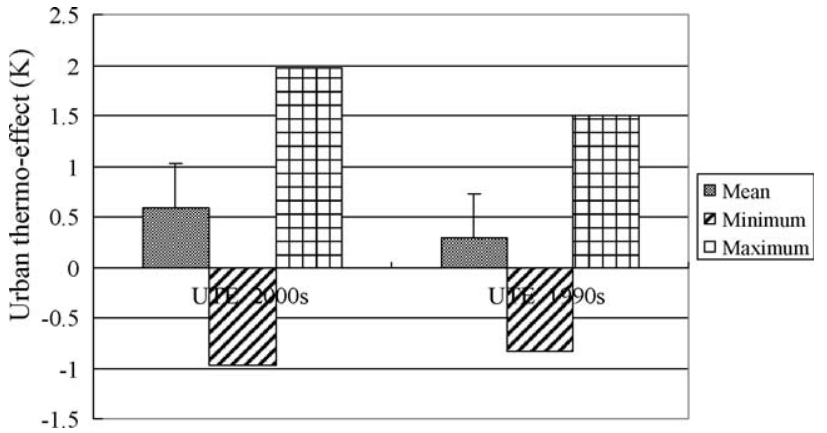

Fig. 3. The maximum, minimum, and mean urban thermo-effect (UTE) in the 2000s and 1990s compared to the 1950s. 2000s were Baotou, Beijing, Shantou, Tangshan, and Changsha, denoting the fact that the southern Chinese cities, such as Shantou and Changsha appeared to manifest the strong urban thermoeffect similar to that manifested by the northern Chinese cities. We could say that as rapid urbanization took place, and the urban built-up area continued to grow bigger in the 2000s, the local factors likewise continued to directly affect the urban thermoeffect. Finally, we can see that the biggest urban thermo-effect is at $1.97 \mathrm{~K}$ degree.

Meanwhile, Fig. 4 shows the distribution of the urban thermoeffect of the selected cities during the 1990s. The stronger positive urban thermo-effect occurred mainly in the northeast Chinese cities, while the negative urban thermo-effect which occurred in the Chinese cities, which lie in the middle and lower reaches of the Yangtze River, may be caused by the regional cooling climate effect of the Yangtze River and its surrounding lakes. Fig. 5 shows the distribution of the urban thermo-effect of the selected cities in the 2000s. The stronger positive urban thermo-effect occurred mainly

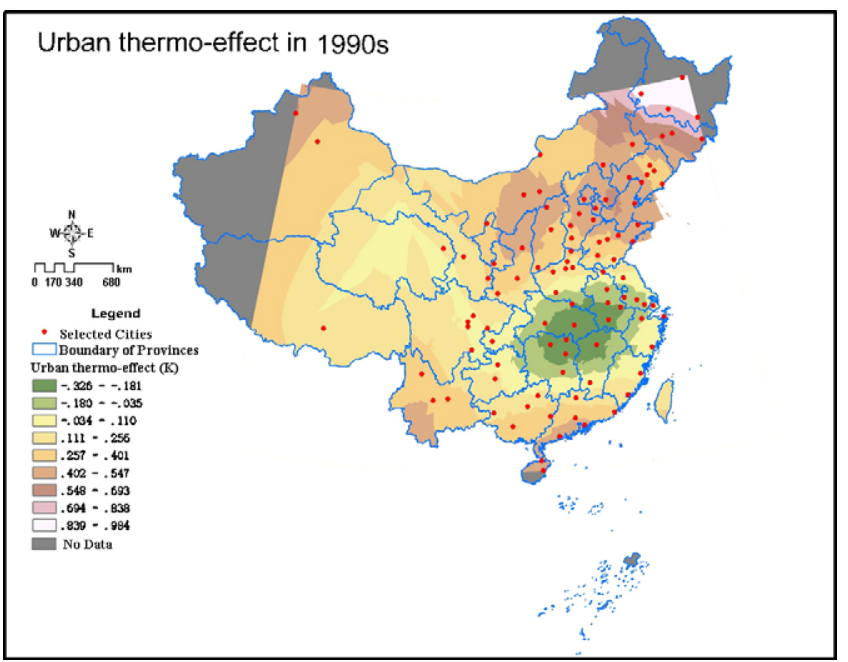

Fig. 4. The spatial distribution of the urban thermo-effect in the 1990s compared to the $1950 \mathrm{~s}$

Table 2

Top five cities with high urban thermo-effect in the 1990s and 2000s.

\begin{tabular}{lllll}
\hline \multicolumn{1}{c}{ 1990s } & & & 2000s & \\
\cline { 1 - 2 } City name & $\begin{array}{l}\text { Urban thermo- } \\
\text { effect }(\mathrm{K})\end{array}$ & & City name & $\begin{array}{l}\text { Urban thermo- } \\
\text { effect }(\mathrm{K})\end{array}$ \\
\hline Qiqihar & 1.5033 & & Baotou & 1.9722 \\
Mudanjiang & 1.2556 & & Beijing & 1.6389 \\
Baotou & 1.1922 & & Shantou & 1.5500 \\
Yichun & 1.1650 & & Tangshan & 1.4125 \\
Shenzhen & 1.0950 & Changsha & 1.3875 \\
\hline
\end{tabular}




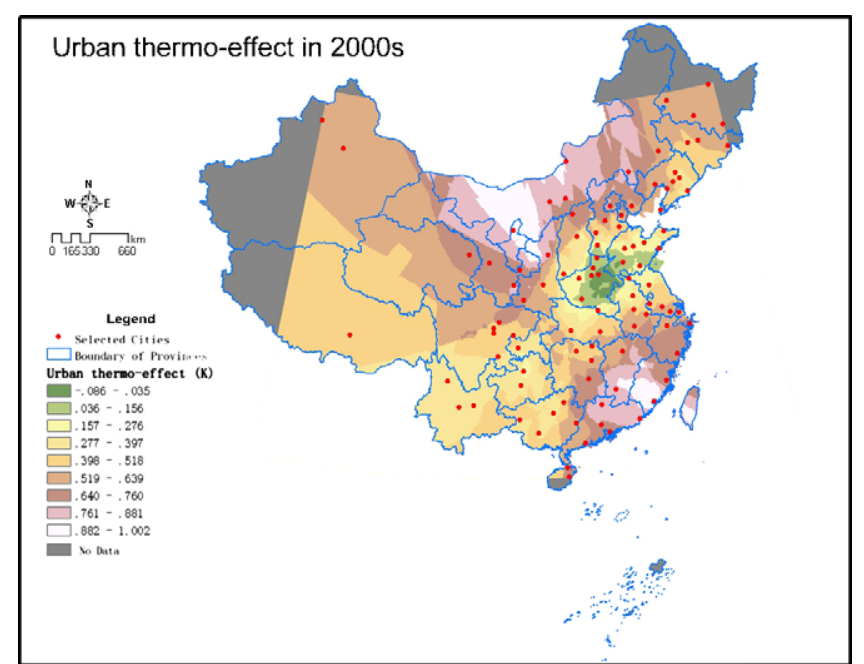

Fig. 5. The spatial distribution of the urban thermo-effect in the 2000s compared to the 1950 s.

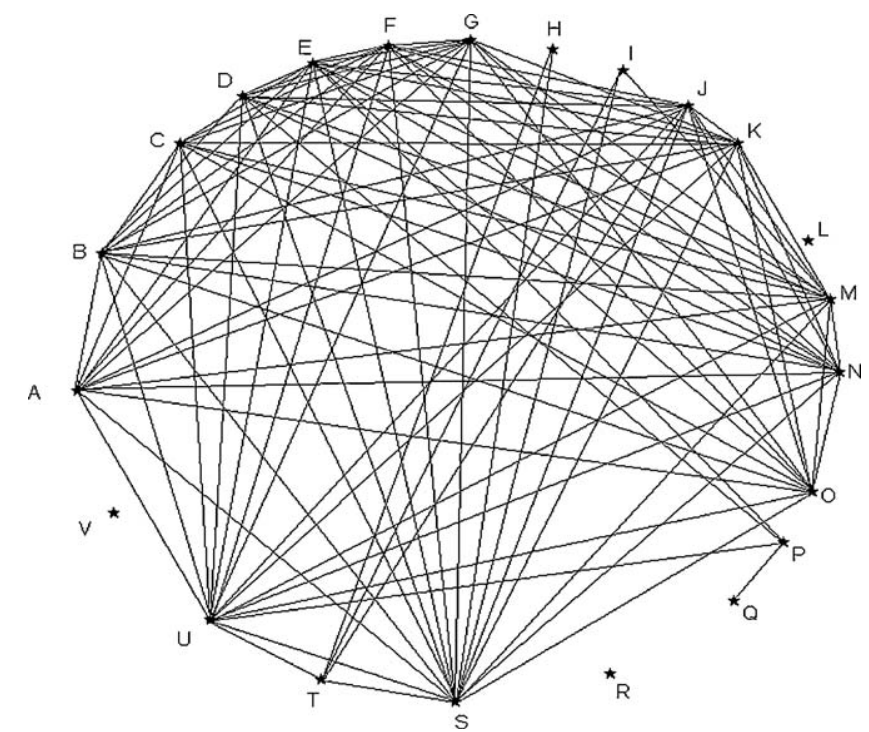

Fig. 6. The system topological graph of urban thermo-effects. Note: Each letter in the figure denotes the same meaning as those presented in Table 1.

Table 3

Grey correlation degree of each pair of factors of the urban thermo-effect.

\begin{tabular}{|c|c|c|c|c|c|c|c|c|c|c|c|}
\hline & A & B & C & $\mathrm{D}$ & $\mathrm{E}$ & $\mathrm{F}$ & G & $\mathrm{H}$ & I & $\mathrm{J}$ & K \\
\hline A & 1.0001 & 0.9354 & 0.9283 & 0.8994 & 0.9212 & 0.9463 & 0.9498 & 0.8707 & 0.8895 & 0.9071 & 0.949 \\
\hline B & 0.9475 & 1.0001 & 0.9425 & 0.9068 & 0.9324 & 0.9289 & 0.9413 & 0.8777 & 0.8952 & 0.9039 & 0.946 \\
\hline$C$ & 0.9275 & 0.9295 & 1.0001 & 0.878 & 0.9022 & 0.9219 & 0.9205 & 0.86 & 0.8764 & 0.8849 & 0.9298 \\
\hline D & 0.9138 & 0.9039 & 0.8966 & 1 & 0.9104 & 0.9032 & 0.9111 & 0.8871 & 0.8888 & 0.9015 & 0.9137 \\
\hline E & 0.9363 & 0.933 & 0.9204 & 0.9139 & 1.0001 & 0.9197 & 0.9329 & 0.8795 & 0.8956 & 0.9026 & 0.9315 \\
\hline $\mathrm{F}$ & 0.9485 & 0.9162 & 0.9257 & 0.8909 & 0.9049 & 1.0001 & 0.9365 & 0.8802 & 0.8947 & 0.9091 & 0.9378 \\
\hline G & 0.9498 & 0.9277 & 0.9213 & 0.8963 & 0.917 & 0.9338 & 1.0001 & 0.8702 & 0.8808 & 0.8893 & 0.9332 \\
\hline $\mathrm{H}$ & 0.891 & 0.8759 & 0.8828 & 0.8889 & 0.8769 & 0.8954 & 0.8905 & 1 & 0.8972 & 0.8897 & 0.8862 \\
\hline I & 0.89 & 0.8747 & 0.8783 & 0.8713 & 0.8748 & 0.8914 & 0.8815 & 0.878 & 1.0001 & 0.8834 & 0.8849 \\
\hline J & 0.9257 & 0.9078 & 0.9089 & 0.9083 & 0.9057 & 0.9247 & 0.9115 & 0.8955 & 0.9052 & 1 & 0.9149 \\
\hline $\mathrm{K}$ & 0.9477 & 0.9318 & 0.929 & 0.897 & 0.9135 & 0.9336 & 0.9315 & 0.8623 & 0.8818 & 0.891 & 1.0001 \\
\hline $\mathrm{L}$ & 0.8635 & 0.8555 & 0.8539 & 0.8599 & 0.8572 & 0.8601 & 0.8583 & 0.8793 & 0.8755 & 0.8684 & 0.8763 \\
\hline M & 0.9419 & 0.9232 & 0.923 & 0.8872 & 0.9008 & 0.9223 & 0.922 & 0.8702 & 0.8939 & 0.9007 & 0.9303 \\
\hline $\mathrm{N}$ & 0.9417 & 0.9277 & 0.9275 & 0.9012 & 0.9136 & 0.9291 & 0.9242 & 0.8857 & 0.9004 & 0.9129 & 0.9302 \\
\hline 0 & 0.9364 & 0.9466 & 0.9315 & 0.8974 & 0.9275 & 0.9208 & 0.9341 & 0.8842 & 0.8999 & 0.9037 & 0.9352 \\
\hline $\mathrm{P}$ & 0.902 & 0.8982 & 0.8992 & 0.9089 & 0.9017 & 0.9044 & 0.9053 & 0.8761 & 0.8933 & 0.8972 & 0.9045 \\
\hline Q & 0.8895 & 0.8852 & 0.8838 & 0.9033 & 0.9019 & 0.8832 & 0.8971 & 0.8688 & 0.8777 & 0.8872 & 0.8868 \\
\hline $\mathrm{R}$ & 0.8589 & 0.8632 & 0.8632 & 0.8664 & 0.8696 & 0.8621 & 0.8661 & 0.855 & 0.8575 & 0.8519 & 0.8623 \\
\hline$S$ & 0.9121 & 0.8908 & 0.9009 & 0.8832 & 0.8861 & 0.9165 & 0.8989 & 0.8813 & 0.9322 & 0.9079 & 0.9081 \\
\hline $\mathrm{T}$ & 0.9118 & 0.899 & 0.9078 & 0.9077 & 0.8979 & 0.9193 & 0.9069 & 0.9206 & 0.9336 & 0.9133 & 0.9116 \\
\hline U & 0.9365 & 0.9258 & 0.9457 & 0.8789 & 0.9037 & 0.9258 & 0.925 & 0.8589 & 0.8801 & 0.8874 & 0.9346 \\
\hline \multirow[t]{2}{*}{ V } & 0.8286 & 0.8228 & 0.8201 & 0.8286 & 0.8221 & 0.8372 & 0.8298 & 0.822 & 0.8234 & 0.8248 & 0.8422 \\
\hline & $\mathrm{L}$ & M & $\mathrm{N}$ & 0 & $\mathrm{P}$ & Q & $\mathrm{R}$ & S & $\mathrm{T}$ & $\mathrm{U}$ & V \\
\hline A & 0.8456 & 0.9464 & 0.9365 & 0.9254 & 0.8795 & 0.8614 & 0.8166 & 0.9161 & 0.8836 & 0.9419 & 0.8027 \\
\hline B & 0.8636 & 0.9419 & 0.9351 & 0.9491 & 0.8956 & 0.8803 & 0.8509 & 0.9131 & 0.8898 & 0.9439 & 0.8297 \\
\hline C & 0.8331 & 0.9281 & 0.9198 & 0.9191 & 0.8745 & 0.8533 & 0.8205 & 0.9043 & 0.8777 & 0.9496 & 0.7912 \\
\hline D & 0.8638 & 0.9103 & 0.9079 & 0.8984 & 0.9035 & 0.8956 & 0.8499 & 0.9043 & 0.896 & 0.9043 & 0.8301 \\
\hline $\mathrm{E}$ & 0.8663 & 0.9247 & 0.9228 & 0.9313 & 0.9 & 0.8985 & 0.8587 & 0.9099 & 0.8895 & 0.927 & 0.8302 \\
\hline $\mathrm{F}$ & 0.847 & 0.9308 & 0.9255 & 0.9111 & 0.8864 & 0.8586 & 0.8265 & 0.9233 & 0.8969 & 0.9346 & 0.8187 \\
\hline G & 0.8394 & 0.928 & 0.917 & 0.9226 & 0.8833 & 0.8703 & 0.8249 & 0.9034 & 0.877 & 0.9312 & 0.8037 \\
\hline $\mathrm{H}$ & 0.885 & 0.8988 & 0.8951 & 0.8871 & 0.8713 & 0.8614 & 0.8401 & 0.9051 & 0.911 & 0.8901 & 0.8265 \\
\hline I & 0.8591 & 0.902 & 0.8924 & 0.8854 & 0.8702 & 0.8485 & 0.8158 & 0.9358 & 0.9123 & 0.8901 & 0.7977 \\
\hline $\mathrm{J}$ & 0.8807 & 0.9252 & 0.924 & 0.9111 & 0.8988 & 0.8872 & 0.8452 & 0.9291 & 0.9092 & 0.9168 & 0.8383 \\
\hline K & 0.8566 & 0.9342 & 0.9219 & 0.9221 & 0.8803 & 0.8548 & 0.8173 & 0.9104 & 0.8809 & 0.9387 & 0.8143 \\
\hline $\mathrm{L}$ & 1.0002 & 0.8689 & 0.8601 & 0.8603 & 0.857 & 0.8595 & 0.8257 & 0.8741 & 0.8881 & 0.8623 & 0.8349 \\
\hline M & 0.84 & 1.0001 & 0.9541 & 0.9374 & 0.87 & 0.8542 & 0.8102 & 0.9188 & 0.8846 & 0.934 & 0.787 \\
\hline $\mathrm{N}$ & 0.8544 & 0.961 & 1 & 0.9355 & 0.8856 & 0.8657 & 0.829 & 0.9206 & 0.895 & 0.9349 & 0.8139 \\
\hline $\mathrm{O}$ & 0.8628 & 0.9508 & 0.9396 & 1 & 0.8844 & 0.8744 & 0.8459 & 0.9181 & 0.8984 & 0.9377 & 0.8259 \\
\hline $\mathrm{P}$ & 0.8683 & 0.9013 & 0.8988 & 0.8917 & 1 & 0.9031 & 0.8661 & 0.8961 & 0.8902 & 0.9015 & 0.8374 \\
\hline Q & 0.8727 & 0.8913 & 0.8832 & 0.8844 & 0.9048 & 1.0003 & 0.8924 & 0.8854 & 0.8826 & 0.8878 & 0.8311 \\
\hline $\mathrm{R}$ & 0.8488 & 0.8637 & 0.8573 & 0.8641 & 0.8743 & 0.8974 & 1.0001 & 0.8628 & 0.8593 & 0.8641 & 0.8327 \\
\hline S & 0.8499 & 0.9211 & 0.91 & 0.9018 & 0.8673 & 0.8504 & 0.814 & 1.0002 & 0.9268 & 0.9168 & 0.797 \\
\hline $\mathrm{T}$ & 0.9048 & 0.919 & 0.9128 & 0.9103 & 0.8968 & 0.888 & 0.8594 & 0.9477 & 1.0002 & 0.9141 & 0.8578 \\
\hline U & 0.8314 & 0.9335 & 0.9222 & 0.9206 & 0.8692 & 0.8486 & 0.8101 & 0.9137 & 0.8767 & 1 & 0.7927 \\
\hline V & 0.8381 & 0.8273 & 0.8244 & 0.8259 & 0.8266 & 0.8172 & 0.8108 & 0.8314 & 0.8383 & 0.8335 & 1.0006 \\
\hline
\end{tabular}

Note: The meanings of each of the letters in each row and column were shown in Table 1. 


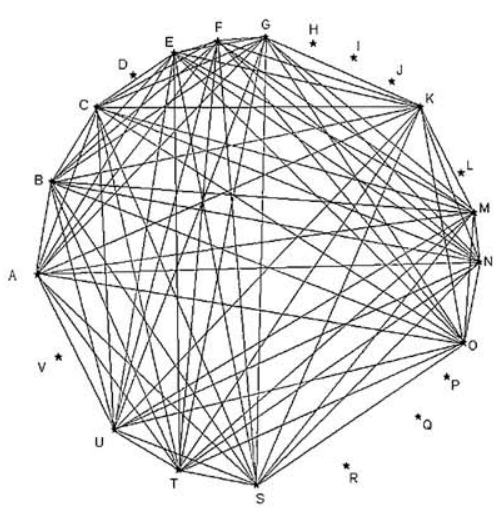

Core 1

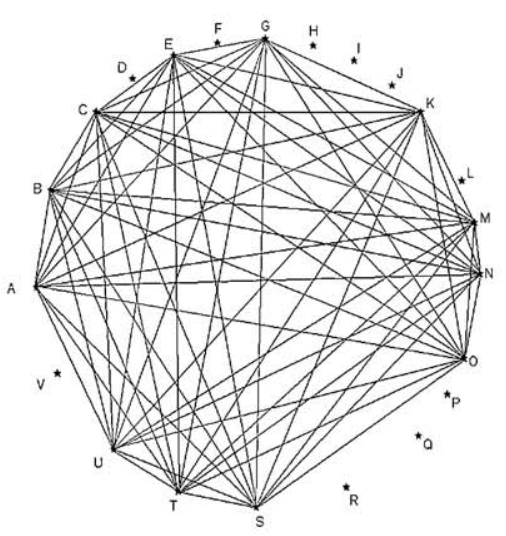

Core 4

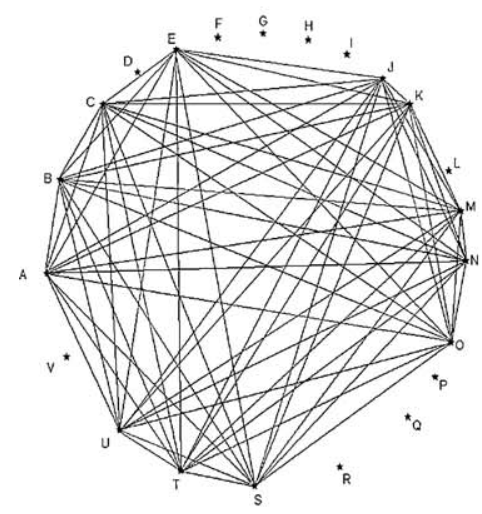

Core 7

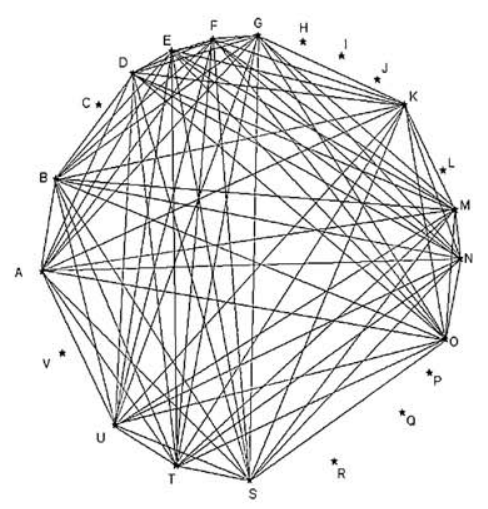

Core 2

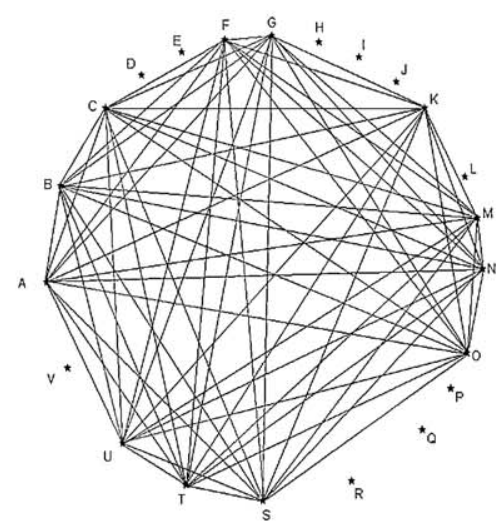

Core 5

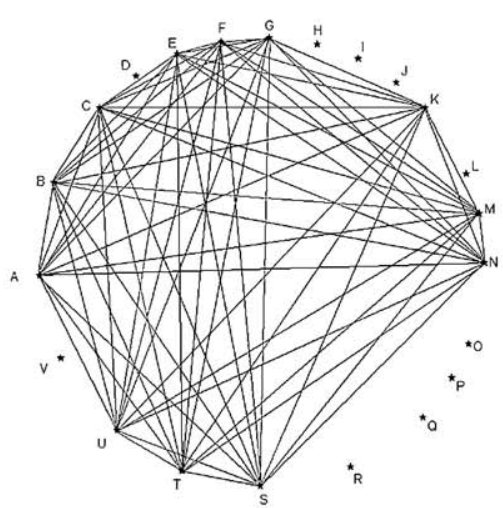

Core 8

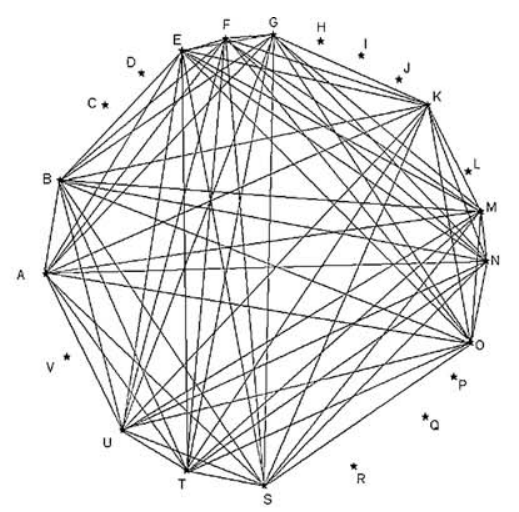

Core 3

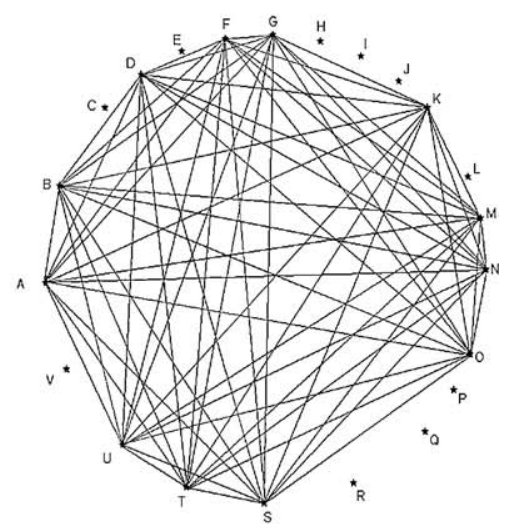

Core 6

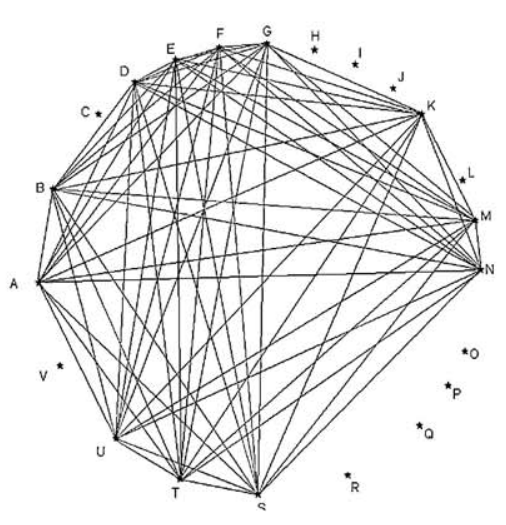

Core 9

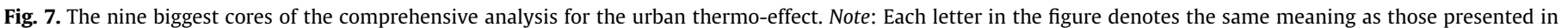
Table 1.

in northwestern cities and southeastern coastal cities, while the negative urban thermo-effect occurred in the middle and northern Chinese plain cities, which may be caused by the regional cooling climate effect of the Huaihe River and its surrounding lakes. The urban thermo-effect is comparable to the change tendency of air mean temperatures from 1951 to 2004 as detected by Ren et al. (2005).

\subsection{Comprehensive ecological analysis of the urban thermo-effects}

3.2.1. Grey correlation degree for every pair of factors compared

Table 3 shows the grey correlation degrees of every pair of factors compared in the study.
Table 4

Table of system core in the urban thermo-effect system.

\begin{tabular}{llllllllllllll}
\hline Core & \multicolumn{11}{c}{ Element of system cores } \\
\hline Core1 & A & B & C & E & F & G & K & M & N & O & S & T & U \\
Core2 & A & B & D & E & F & G & K & M & N & O & S & T & U \\
Core3 & A & B & E & F & G & K & M & N & O & S & T & U & \\
Core4 & A & B & C & E & G & K & M & N & O & S & T & U & \\
Core5 & A & B & C & F & G & K & M & N & O & S & T & U & \\
Core6 & A & B & D & F & G & K & M & N & O & S & T & U & \\
Core7 & A & B & C & E & J & K & M & N & O & S & T & U & \\
Core8 & A & B & C & E & F & G & K & M & N & S & T & U & \\
Core9 & A & B & D & E & F & G & K & M & N & S & T & U & \\
\hline
\end{tabular}

Note: Each letter in the figure denotes the same meaning as those presented in Table 1. 

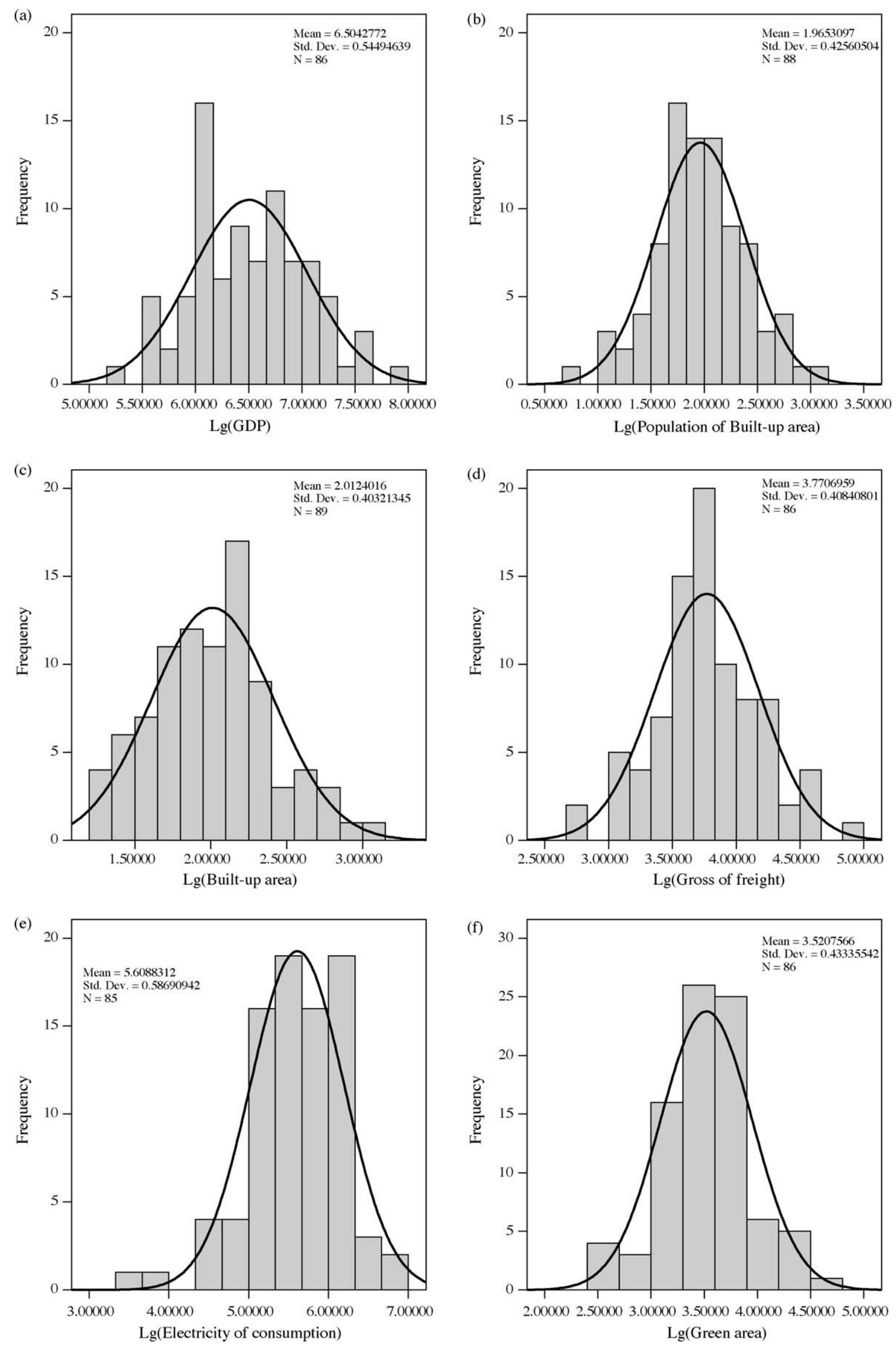

Fig. 8. Statistical distribution of the six main factors' data with logarithmic treatment. 


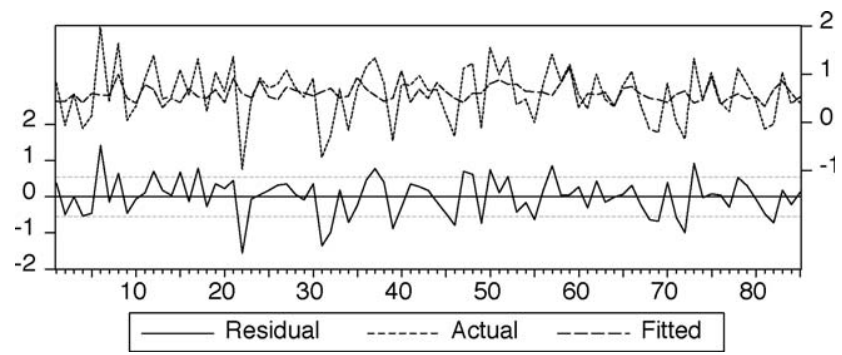

Fig. 9. Fitting residual error graph of the comprehensive ecological model of the urban thermo-effect. Note: The term "residual" is the curve of residual error, and residual error $=$ real value - simulated value; The term "actual" is the curve real value of the urban thermo-effect; The term "fitted" is the curve of the simulated value of the urban thermo-effect.

\subsubsection{System core and coritivity of the urban thermo-effects}

Fig. 6 represents the topological graph of 22 selected factors for the comprehensive analysis of the urban thermo-effect where the grey correlation degree is over 0.9 . After the calculation of system core in this t topological graph, we find that the coritivity is 8 , and that there are hundreds of cores in the system. We only listed nine bigger cores of the system (the number of elements contained in the system is more than 12), all of which are shown in Fig. 7 and Table 4

We can conclude from Table 4 that Core 1 is the key core of the urban thermo-effect comprehensive analysis system with elements that include: A (GDP of the built-up area), B (population of the built-up area), C (size of the built-up area), E (gross of freight), $\mathrm{F}$ (water consumption annually), G (annual electricity consumption), $\mathrm{K}$ (road area at the end of the year), $\mathrm{M}$ (number of buses for commercial use at the end of the year), $\mathrm{N}$ (number of public buses), $O$ (number of taxis at the end of the year), $S$ (gardening green area), $\mathrm{T}$ (green area per person), and $\mathrm{U}$ (green area of built-up area).

3.2.3. The main factors for the comprehensive ecological analysis of urban thermo-effect

Upon careful observation of the system core (Core1), we discovered that although some factors have a high correlation with others, their actual meaning was insignificant; thus we named them as the redundant set of the aforementioned system core. Due to the fact that the practical meaning of each factor was neglected and only the relationship between each factor was considered in calculating the grey correlation degree, it must be simplified based on the practical meaning to determine the final indicators for the comprehensive ecological analysis of the urban thermo-effect. Considering the $\mathrm{O}, \mathrm{S}, \mathrm{T}$, and $\mathrm{U}$ elements in the system core (Core1), they definitely have a more profound relationship and a high grey correlation degree with each other. In actuality, however, they have the same meaning and belong to the same attribute index, so we can only choose a single element among them.

Finally, we arrive at A, B, C, E, G, and $\mathrm{U}$ as the elements that comprise the main factors for the comprehensive ecological analysis of the urban thermo-effects.

\subsubsection{Comprehensive ecological model of the urban thermo-effect}

Using the One Sample Kolmogorov-Smirnov test in the SPSS software upon completion of the logarithmic treatment of the factor-related data, we found that the Asymp.Sig. (2-tailed) parameters were bigger than 0.05 , which gave significant confidence on the normal distribution of all factor-related data with the same logarithmic treatment (Fig. 8). To improve the quality of the multiple regression analysis, the basic theoretical
Table 5

List of the statistical characteristics of the comprehensive ecological model of the urban thermo-effect.

\begin{tabular}{lcccc}
\hline & Coefficient & \multicolumn{1}{l}{ S.E. } & \multicolumn{1}{c}{$t$-Statistic } & Prob. \\
\hline$C_{1}$ & -0.149137 & 0.740419 & -0.201422 & 0.8409 \\
$C_{2}$ & 0.077660 & 0.206139 & 0.376737 & 0.7074 \\
$C_{3}$ & 0.093100 & 0.417513 & 0.222986 & 0.8241 \\
$C_{4}$ & 0.510248 & 0.286191 & 1.782893 & 0.0784 \\
$C_{5}$ & -0.054185 & 0.252436 & -0.214650 & 0.8306 \\
$C_{6}$ & -0.229143 & 0.218886 & -1.046862 & 0.2984 \\
\hline$R^{2}$ & 0.697543 & Mean dependent var. & 0.601049 \\
Adjusted $R^{2}$ & 0.040426 & S.D. dependent var. & 0.556377 \\
S.E. of regression & 0.545015 & Akaike info criterion & 1.691967 \\
Sum squared residual & 23.46629 & Schwarz criterion & 1.864390 \\
Log likelihood & -65.90860 & F-statistic & 1.707765 \\
Durbin-Watson stat & 2.119221 & Prob. (F-statistic) & 0.042494 \\
\hline
\end{tabular}

form of the model is decided as follows:

$$
\begin{aligned}
\Delta T= & C_{1}+C_{2} \lg x_{1}+C_{3} \lg x_{2}+C_{4} \lg \left(x_{3}-x_{6}\right)+C_{5} \lg x_{4} \\
& +C_{6} \lg x_{5}
\end{aligned}
$$

where $C_{1}, C_{2}, C_{3}, C_{4}, C_{5}$, and $C_{6}$ represent the undetermined statistical parameters, $x_{1}$ denotes the GDP of the built-up area, $x_{2}$ denotes the population of the built-up area, $x_{3}$ denotes the size of the built-up area, $x_{4}$ denotes gross of freight, $x_{5}$ denotes annual electricity consumption, and $x_{6}$ denotes the green area of built-up area.

Fig. 9 is the fitting residual error graph of the comprehensive ecological model of the urban thermo-effect. Table 5 shows the results arrived at after performing the $F$-test: $R^{2}$ (correlation coefficient $)=0.69$, S.E. ( standard error) $=0.55$, and value $P=0.04$ $\leq 0.05$, which passed the test.

Integrating all the above indicators analysis, we produced the final form of the model:

$$
\begin{aligned}
\Delta T= & 0.08 \times \lg x_{1}+0.09 \times \lg x_{2}+0.51 \times \lg \left(x_{3}-x_{6}\right)+0.05 \\
& \times \lg x_{4}+0.23 \times \lg x_{5}-0.15
\end{aligned}
$$

where $\Delta T$ denotes the urban thermo-effect; $x_{1}$ denotes the GDP of the built-up area; $x_{2}$ denotes the population of the built-up area; $x_{3}$ denotes the size of the built-up area; $x_{4}$ denotes gross of freight; $x_{5}$ denotes annual electricity consumption, and $x_{6}$ denotes green area of built-up area.

\section{Conclusions}

Using 89 major Chinese cities which comprise the case study area, this article carried out a comprehensive ecological analysis of the urban thermo-effect in the past 50 years. The results indicated that the urban thermo-effect in the 2000s was stronger that in the 1990s. The maximum urban thermo-effect in the 2000s compared to that in the $1950 \mathrm{~s}$ was at $1.97 \mathrm{~K}$, while the maximum urban thermo-effect in the 1990s compared to that in 1950s was at $1.50 \mathrm{~K}$. Through the distribution analysis of the urban thermoeffect in the 1990s and 2000s, the results showed that the strong positive urban thermo-effect mainly occurred in northeastern Chinese cities during the 1990s, while it occurred in the northwestern cities and southeastern coastal cities during the 2000s, which could be the main contribution of the local factors such as rapid urbanization in China around that time.

After the grey correlation degree analysis and system core and coritivity computation for all the selected local factors, it can be concluded that the main factors for the comprehensive ecological analysis of the urban thermo-effect are the following six factors: GDP, population, and size of the built-up area, as well as gross of 
freight, annual electricity consumption, and green area of built-up area.

Using these six main factors, we created a comprehensive ecological model of the urban thermo-effect through multiple regression analysis, which is reliable for the analysis and prediction of this phenomenon in future urban development endeavors. This is because the residual error of the created model is smaller than $0.5 \mathrm{~K}$. It can also be concluded that the mitigation of urban temperature increase is possible through the adjustment of the abovementioned artificial controllable factors.

The findings in this article could provide references in carrying out urban planning and implementation policies in the national and local scale, as well as urban planning and construction of other developing countries with rapid rates of urbanization and economic development.

\section{Acknowledgments}

We would like to acknowledge the support of three foundations: one National Nature Science Foundation of China (70433001), and two Knowledge Innovation Project of The Chinese Academy of Sciences (KZCX2-YW-422 and KZCX2-YW-324). We are also grateful to the help extended by our colleagues from the Research Centre of Eco-Environmental Sciences, The Chinese Academy of Sciences and the reviewers who helped me improve the article.

\section{References}

Aikawa, M., Hiraki, T., Eiho, J., 2006. Vertical atmospheric structure estimated by heat island intensity and temporal variations of methane concentrations in ambient air in an urban area in Japan. Atmospheric Environment 40, 43084315.

Chang, T.C., Lin, S.J., 1999. Grey relation analysis of carbon dioxide emissions from industrial production and energy uses in Taiwan. Journal of Environmenta Management 56, 247-257.

Deng, J.L., 1982. Control problems of grey systems. Systems \& Control Letters 1, $288-294$.

Deng, J.L., 1988. Properties of relational space for grey systems. In essential topics on grey system-theory and applications. China Ocean 1-13 (in Chinese, with English abstract).

Deng, J.L., 1989. Introduction to grey system theory. The Journal of Grey System 1, $1-24$.

Djen, C.S., 1992. The urban climate of shanghai. Atmospheric Environment, Part B Urban Atmosphere 26, 9-15.

Dresner, M., 2008. Using research projects and qualitative conceptual modeling to increase novice scientists' understanding of ecological complexity. Ecological Complexity 5, 216-221.

Fan, H., Sailor, D.J., 2005. Modeling the impacts of anthropogenic heating on the urban climate of Philadelphia: a comparison of implementations in two PBL schemes. Atmospheric Environment 39, 73-84.

Green, D.G., Sadedin, S., 2005. Interactions matter-complexity in landscapes and ecosystems. Ecological Complexity 2, 117-130.

Kalkstein, L.S., 1993. Health and climate change-direct impacts in cities. The Lancet 342, 1397-1399.

Kalkstein, L.S., Greene, J.S., 1997. An evaluation of climate/mortality relationships in large U.S. Cities and the possible impacts of a climate change. Environmental Health Perspectives 105 (1), 84-93.
Kardinal Jusuf, S., Wong, N.H., Hagen, E., Anggoro, R., Hong, Y., 2007. The influence of land use on the urban heat island in Singapore. Habitat International 31, 232242

Li, B.L., 2000. Why is the holistic approach becoming so important in landscape ecology? Landscape Urban Plan 50 (1-3), 27-41.

Le Comte, D.M., Warren, H.E., 1981. Modeling the impact of summer temperatures on national electricity consumption. Journal of Applied Meteorology 20, 14151419.

Li, D.K., Yang, Z.S., Sun, X.G., 2002. Study on Prolonging the Live Age of the Qingshuigou Channel of the Yellow River Estuary. Yellow River Water Conservancy Press, Zhengzhou (in Chinese).

Li, J.J., et al., 2009. Remote sensing evaluation of urban heat island and its spatial pattern of the Shanghai metropolitan area, China. Ecological Complexity, doi:10.1016/j.ecocom.2009.02.002.

Li, Q., Zhang, H., Liu, X., Huang, J., 2004. Urban heat island effect on annual mean temperature during the last 50 years in china. Theoretical and Applied Climatology $79,165-174$

Liu, S.F., 2003. Emergence and development of grey system theory and its forward trends. Journal of Zhejiang Wanli University 16, 14-17 (in Chinese, with English abstract).

Lu, M., Wevers, K., 2007. Grey system theory and applications: a way forward. Journal of Grey System 10, 47-54.

Ma, S.J., Wang, R.S., 1984. The social-economic-natural complex ecological system. Acta Ecologica Sinica 4, 1-9 (in Chinese, with English abstract).

Noyes, P.D., McElwee, M.K., Miller, H.D., Clark, B.W., Van Tiem, L.A., Walcott, K.C., Erwin, K.N., Levin, E.D., 2009. The toxicology of climate change: environmental contaminants in a warming world. Environment International 35, 971-986.

Oke, T.R., 1973. City size and the urban heat island. Atmospheric Environment 7, 769-779.

Oke, T.R., 1982. The energetic basis of the urban heat island. Quarterly Journal of the Royal Meteorological Society 108, 1-24.

Oke, T.R., 1988. The urban energy balance. Progress in Physical Geography 12, 471508.

Qiao, B., Fang, C., Ban, M., 2006. Investigation of the interactive, intimidating relation between urbanization and the environment in an arid area based on grey system theory. Journal of China University of Mining and Technology 16 452-456 (in Chinese, with English abstract).

Ren, G.R., Xu, M.Z., Chu, Z.Y., Guo, J., Li, Q.Y., Liu, X.N., Wang, Y., 2005. Changes of surface air temperature in china during 1951-2004. Climatic and Environmental Research 10, 717-727 (in Chinese, with English abstract).

Santamouris, M., Papanikolaou, N., Livada, I., Koronakis, I., Georgakis, C., Argiriou, A. Assimakopoulos, D.N., 2001. On the impact of urban climate on the energy consumption of buildings. Solar Energy 70 (3), 201-216.

Sarrat, C. Lemonsu, A. Masson, V. Guedalia, D. 2006. Impact of urban heat island on regional atmospheric pollution. Atmospheric Environment 40, 1743-1758.

Semenza, J.C., Rubin, C.H., Falter, K.H., Selanikio, J.D., Flanders, W.D., Howe, H.L., Wilhelm, J.L., 1996. Heat-related deaths during the July 1995 heat wave in Chicago. The New England Journal of Medicine 335 (2), 80-90.

Smoyer, K.E., 1998. A comparative analysis of heat waves and associated mortality in St. Louis, Missouri-1980 and 1995. International Journal of Biometeorology 42, 44-50.

Taha, H., 1997. Urban climates and heat islands: Albedo, evapotranspiration, and anthropogenic heat. Energy and Buildings 25, 99-103.

Wang, Y.L., Xu, J., Xi, Y.M., 1993a. The core and coritivity of a system (i). Journal of System Engineering and Electronics 4, 28-34 (in Chinese, with English abstract).

Wang, Y.L., Xu, J., Xi, Y.M., 1993b. The core and coritivity of a system (iv). Journal of System Engineering and Elect ronics. 4, 28-34.

Weng, Q., Yang, S., 2004. Managing the adverse thermal effects of urban development in a densely populated Chinese city. Journal of Environmental Management 70, 145-156.

Xiao, R.B., Weng, Q.H., Ouyang, Z.Y., Li, W.F., Schienke, E.W., Zhang, Z.M., 2008. Land surface temperature variation and major factors in Beijing, China. Photogrammetric Engineering and Remote Sensing 74, 451-461.

$\mathrm{Xu}, \mathrm{J} ., 1999$. The core and coritivity of a system (vii)-subcore and an algorithm of coritivity. Journal of System Engineering 14, 243-246 (in Chinese, with English abstract). 